\title{
To DAIR or not to DAIR: Decision-making in the management of acute prosthetic joint infection - A narrative review
}

\author{
Jaime Lora-Tamayo*, Mikel Mancheño-Losa, and Carlos Lumbreras \\ Department of Internal Medicine, Hospital Universitario 12 de Octubre, Instituto de Investigación "i+12" Hospital 12 de Octubre, Madrid, Spain
}

\begin{abstract}
Prosthetic joint infections are much-feared complications of joint arthroplasty that require complex multidisciplinary treatment. Although prosthesis removal is usually needed, the performance of debridement, antibiotics, and implant retention (DAIR) is an attractive alternative in well-selected patients with acute infection. Whether or not to indicate DAIR in a given situation is not a straightforward decision, despite validated algorithms and published guidelines. The odds of eradicating the infection and retaining an arthroplasty that is functional and painless are influenced by multiple variables regarding not only type of infection but also causative microorganism, antimicrobial treatment, surgical procedure, and the patient's condition and baseline characteristics. In this narrative review, we go over current recommendations, and algorithms, along with reported rates of success and risk factors of failure, and we will balance the decision to perform DAIR against other alternatives.
\end{abstract}

Key words: Debridement. Irrigation. Functional outcome. Foreign body infection. Arthroplasty.

\section{Clinical case}

An 81-year-old male with hypertension and a left total knee prosthesis needed a cemented arthroplasty due to a left hip fracture some years ago. The patient has no cognitive impairment and is independent in routine activities. The patient recently fell and presented with periprosthetic hip fracture. A revision procedure was performed, in which the femoral component of the prosthesis was replaced by a new device with a longer cemented stem. Six weeks after that surgery, the patient presented in the emergency room with 10 days of fever $\left(38.0^{\circ} \mathrm{C}\right)$, along with tenderness and signs of inflammation over the surgical wound. No sinus tract was observed. C-reactive protein (CRP) was $12.5 \mathrm{mg} /$ $\mathrm{dL}$ (normal range $<0.5 \mathrm{mg} / \mathrm{dL}$ ). Until the symptoms started, the prosthesis seemed to perform well, and
X-rays showed no signs of loosening or infection. How should this patient be managed?

\section{Introduction}

The most feared complication of joint arthroplasty is prosthetic joint infection (PJI). While infrequent in relative terms, the absolute number of episodes is rising in parallel with the life expectancy of the population and the increasing number of devices placed ${ }^{1,2}$. As with foreign body infection, an infected prosthetic device is characterized by the presence of bacterial biofilm, in which microorganisms undergo phenotypic and metabolic change, become tolerant to antibiotics, and are able to evade the host's immune system ${ }^{3}$. The management of PJI, therefore, is complex and commonly

Visual abstract available at https://www.spanishjmed.com/frame_esp.php?id=42

Corrrespondence:

*Jaime Lora-Tamayo

E-mail: jaime@lora-tamayo.es
Date of reception: 21-01-2021

Date of acceptance: 24-03-2021

DOI: 10.24875/SJMED.M21000010
Available online: 21-06-2021 Span J Med. 2021;1(2):119-131

www.spanishjmed.com 2696-5631 / @ 2021 Sociedad Española de Medicina Interna. Published by Permanyer. This is an open access article under the CC BY-NC-ND license (http://creativecommons.org/licenses/by-nc-nd/4.0/). 


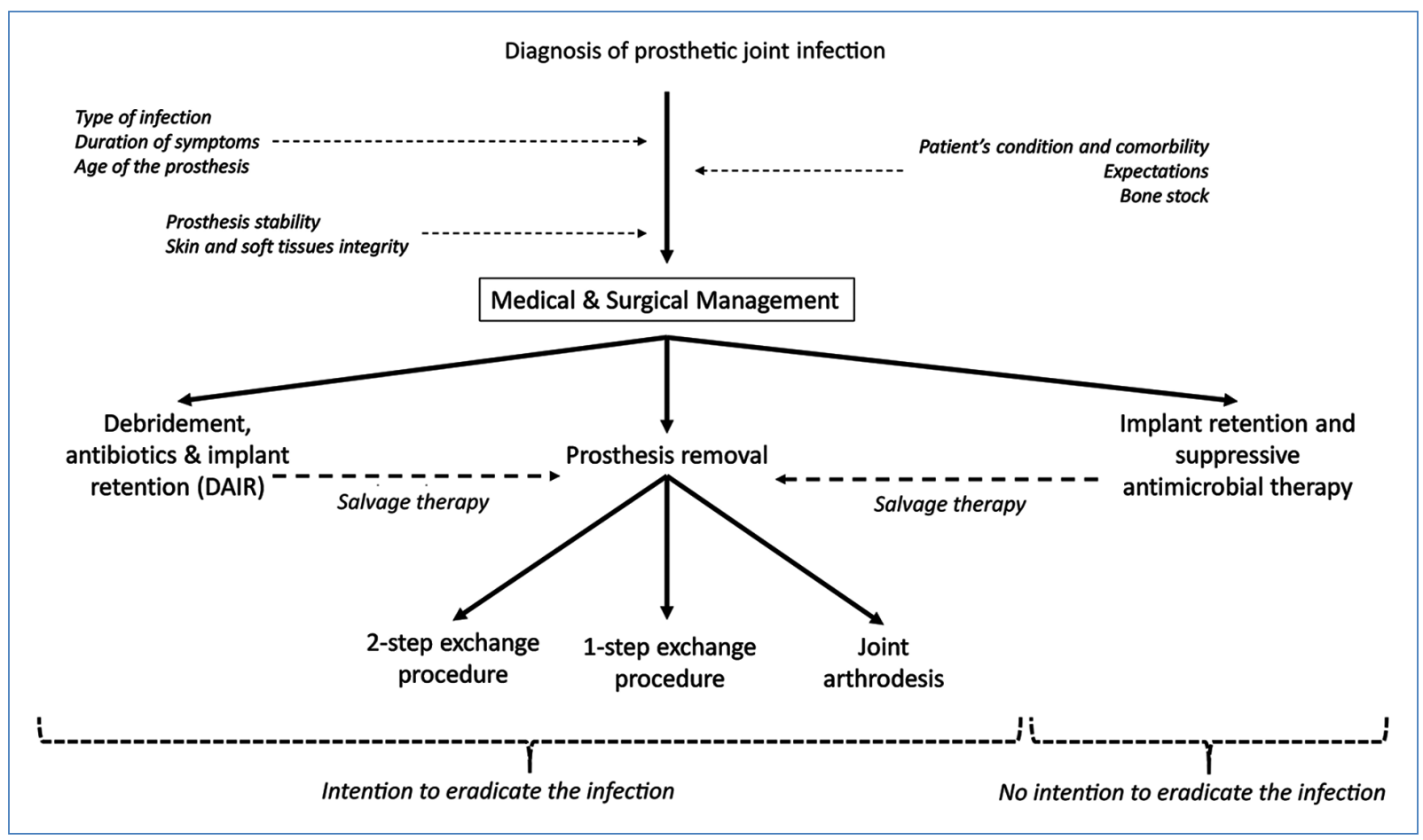

Figure 1. Surgical and medical options for prosthetic joint infection (adapted from Ariza et al. ${ }^{10}$ ).

requires aggressive surgery and optimized antimicrobial treatment, posing a significant economic burden for the health-care system and a considerable psychological stress for the patient ${ }^{4-8}$.

Decision-making in PJI is not straightforward and should be made on an interdisciplinary basis, with the involvement of orthopedic surgeons, microbiologists, and clinicians with experience in the management of bone and joint infections. The patient's condition, expectations, and personal preferences should also form part of the final decision. The goals of treatment are to eradicate infection and maintain painless joint function $^{2,9}$. While multiple surgical and clinical variables should be taken into account, there are basically three main options, two of them with an eradicative intention and a third, non-eradicative one (Fig. 1) ${ }^{10}$.

Among the options for microbial eradication, prosthesis removal is the reference treatment, as is the rule with the infections associated with other medical devices such as pacemakers, intravenous catheters, and cerebrospinal shunt devices ${ }^{11}$. Whether prosthesis extraction is followed by definite arthrodesis, one-step revision, or two-step exchange procedure, the common denominator of this strategy is to remove the foreign body and the bacterial biofilm, which significantly facilitates the healing of the infection ${ }^{12-14}$. The two-stage revision is considered to be the gold standard procedure, with high rates of success $(11 \% \text {, range } 0-25 \%)^{15}$, although comparable results have been reported in single-stage revisions in well-selected patients ${ }^{16}$.

However, several drawbacks of removing the prosthesis should also be considered. First, it is not easy to remove a soundly fixed cemented prosthesis and commonly requires a longitudinal osteotomy during long operations. This type of surgery may be too aggressive for frail elderly patients such as the one described in the clinical case, especially if infection presents with sepsis and a significant worsening of the patient's condition. Second, prosthesis exchange depletes bone stock, which is an important issue in elderly patients with a revision prosthesis, but also in younger patients with many years ahead of them who may require further revisions ${ }^{17,18}$. The patient depicted here had a revision hip prosthesis and a knee prosthesis on the same limb, leaving little space for anchoring a new revision device. Third, implant removal followed by replacement with a new prosthesis is not always guaranteed, and some patients may be left with joint arthrodesis and a poor functional situation. Furthermore, amputation may be needed in the most dramatic 
scenarios. Finally, the two-step exchange procedure needs at least two surgeries, with impaired function between procedures.

Debridement, antibiotics, and implant retention (DAIR) provides an alternative curative treatment ${ }^{10,13,19}$. When applied to well-selected patients, it can cure infection, avoid the disadvantages mentioned above, and achieve good results in terms of functional outcome and patient satisfaction ${ }^{17,20}$. Notwithstanding, the real odds of curing the infection when DAIR is attempted may be very different when it comes to specific episodes of PJI, even when the basic conditions for indicating this strategy are met. Performance of DAIR is discouraged when the pre-operative risk of failure is unacceptably high ${ }^{21}$. In this context, several studies have identified risk factors for failure that can significantly reduce the likelihood of success ${ }^{22-49}$ and there are also published risk scores that set out to quantify this probability ${ }^{50,51}$.

In line with the multidisciplinary nature of decision-making in the PJI setting, multiple variables and questions need to be considered when deciding whether to remove a prosthesis or attempt DAIR. In this narrative review, our aim is to go over the relevant evidence and the key factors involved in this decision. Here, we review the current recommendations and decision algorithms, together with the reported rates of success and risk factors for failure, and evaluate the decision to perform DAIR against other alternatives.

\section{Search strategy}

We searched the PubMed database for publications addressing the variables that influence the outcome of DAIR, combining the search terms "DAIR," "debridement," "irrigation," "guidelines," "review," "salvage therapy," "PJI," and "arthroplasty." Abstracts were reviewed and relevant full-length papers were read, as appropriate. We also went through the references in these articles to select previous original papers of relevance. Articles focused on the management of PJIs other than DAIR (i.e., one-step exchange procedure, staged revision, and suppressive antimicrobial therapy) were discarded. Our search was restricted to articles written in English, French, and Spanish.

\section{Current recommendations for performing DAIR: the paradigm and its fissures}

The choice of suitable candidates for DAIR is paramount to its success. Zimmerli's algorithm ${ }^{19}$ is the basis of the current guidelines and is generally accepted in everyday practice and by many scientific societies (Table 1) $10,21,52,53$. According to these recommendations, the infection should be acute (either early post-surgical or hematogenous) and the duration of symptoms short (i.e., less than 21 days), the infected prosthesis should be soundly fixed (i.e., not loose), and the surrounding skin and soft tissues in good condition. Ideally, the causative microorganism should be susceptible to antimicrobials with good activity against biofilm-embedded bacteria, although this information may not be available at the moment of making the decision ${ }^{19,21}$. These conditions aim to select infections where the biofilm is not too mature and is, therefore, more susceptible to surgical debridement and antimicrobial therapy ${ }^{9,54}$. These criteria also stress the need to select devices that are worth the effort of performing DAIR, since there would be no point attempting to retain a loose or exposed prosthesis. Zimmerli's algorithm is simple and consistent, and various observational studies have shown that the prognosis for patients undergoing DAIR who meet these conditions is significantly better than for those who do not ${ }^{55-57}$.

Nevertheless, implementing Zimmerli's rules in any given situation involve reconciling two different aspects of the same problem. On the one hand, a substantial number of patients could benefit from the DAIR strategy even if they do not meet all the conditions of the algorithm, and on the other, a significant percentage of patients fail after DAIR despite meeting those conditions. In this context, the rates of failure after DAIR reported in published series vary widely, ranging from $8 \%$ to $82 \%{ }^{22-49}$. While this surely reflects heterogeneity across studies, and also in the application of the algorithm, it also suggests that there are other important variables with a significant influence on prognosis.

With respect to the first issue, the definition of acute infection can be somewhat variable. It is based, as mentioned, on two chronological criteria involving the type of PJI (early post-operative and hematogenous infections) and duration of infection. Early post-surgical PJIs are those whose symptoms begin a few weeks after prosthesis placement, although the specific cut-off has changed over time. In 1996, Tsukayama et al. set the limit at 1 month $^{38}$. In Zimmerli's pivotal randomized clinical trial of 1998, patients with post-operative infection underwent DAIR if the orthopedic hardware had been in place for 2 months or less ${ }^{58}$. Later, in a reference review, early infections were those that presented within the first 3 months after the index surgery ${ }^{19}$. Finally, the current IDSA guidelines once again set the cut-off at 1 month ${ }^{52}$. 
Table 1. Conditions needed for indicating DAIR

\begin{tabular}{|c|c|c|c|c|c|c|c|}
\hline \multirow[t]{2}{*}{ Reference } & \multicolumn{3}{|c|}{ Type of infection } & \multirow{2}{*}{$\begin{array}{l}\text { Short } \\
\text { duration } \\
\text { of symptoms }\end{array}$} & \multirow{2}{*}{$\begin{array}{l}\text { Skin and soft } \\
\text { tissues in good } \\
\text { condition }\end{array}$} & \multirow{2}{*}{$\begin{array}{l}\text { Prosthesis } \\
\text { stability }\end{array}$} & \multirow{2}{*}{$\begin{array}{l}\text { Microorganisms } \\
\text { to avoid }\end{array}$} \\
\hline & Hematogenous & $\begin{array}{l}\text { Early } \\
\text { post-operative }\end{array}$ & $\begin{array}{l}\text { Late/chronic } \\
\text { post-operative }\end{array}$ & & & & \\
\hline $\begin{array}{l}\text { Zimmerli } \\
\text { et al., } \\
2004^{19}\end{array}$ & Yes & $\begin{array}{l}\text { Yes } \\
\text { (<3 months) }\end{array}$ & $\begin{array}{l}\text { No } \\
\text { (>3 month) }\end{array}$ & $<21$ days & $\begin{array}{l}\text { Required. } \\
\text { No sinus tract }\end{array}$ & Required & $\begin{array}{l}\text { Non-susceptible } \\
\text { to biofilm-active } \\
\text { antibiotics }\end{array}$ \\
\hline $\begin{array}{l}\text { Del Pozo } \\
\text { and Patel, } \\
2009^{2}\end{array}$ & Yes & $\begin{array}{l}\text { Yes } \\
\text { (<3 months) }\end{array}$ & $\begin{array}{l}\text { No } \\
\text { (>3 months) }\end{array}$ & $<21$ days & $\begin{array}{l}\text { Required. } \\
\text { No abscess or } \\
\text { sinus tract }\end{array}$ & Required & $\begin{array}{l}\text { MDR, SCV } \\
\text { S. aureus, } \\
\text { enterococci, } \\
\text { fungus, } \\
\text { quinolone-resistant } \\
\text { P. aeruginosa }\end{array}$ \\
\hline $\begin{array}{l}\text { Osmon } \\
\text { et al., } \\
2013^{52} \\
\text { (IDSA) }\end{array}$ & Yes & $\begin{array}{l}\text { Yes } \\
\text { (<1 month, } \\
\text { approximately) }\end{array}$ & $\begin{array}{l}\text { No } \\
\text { (>1 month) }\end{array}$ & $<21$ days & $\begin{array}{l}\text { Required. } \\
\text { No sinus tract }\end{array}$ & Required & $\begin{array}{l}\text { Non-susceptible } \\
\text { to biofilm-active } \\
\text { antibiotics }\end{array}$ \\
\hline $\begin{array}{l}\text { SPILF, } \\
2014^{53}\end{array}$ & Yes & $\begin{array}{l}\text { Yes } \\
\text { (<1 month)* }\end{array}$ & $\begin{array}{l}\text { No } \\
\text { (> } 1 \text { month) }\end{array}$ & $<10-21$ days & Required & Required & - \\
\hline $\begin{array}{l}\text { Ariza et al., } \\
2017^{10} \\
\text { (SEIMC) }\end{array}$ & Yes & $\begin{array}{l}\text { Yes } \\
(<3 \text { months })\end{array}$ & $\begin{array}{l}\text { No } \\
\text { (>3 months) }\end{array}$ & $<21$ days & Required & Required & $\begin{array}{l}\text { Caution when } \\
\text { there is } \\
\text { impossibility of } \\
\text { using rifampin/ } \\
\text { fluoroquinolones }\end{array}$ \\
\hline ICM, $2019^{21}$ & Yes & $\begin{array}{l}\text { Yes } \\
\text { (not specified) }\end{array}$ & Discouraged & $<28$ days & Required & Required & - \\
\hline
\end{tabular}

*In a document from 2010, SPILF recommended a prosthesis age $<2$ weeks for considering DAIR ${ }^{82}$

IDSA: Infectious Diseases Society of America; SPILF: Société de Pathologie Infectieuse de Langue Française; ICM: International Consensus Meeting (Philadelphia, USA); SEIMC: Sociedad de Enfermedades Infecciosas y Microbiología Clínica (Spain); MDR: multidrug resistant; SCV: small colony variant.

While there is little debate about discouraging DAIR in patients whose symptoms begin subacutely after the $3^{\text {rd }}$ month following the index surgery (i.e., chronic postoperative infections), there continues to be some discussion about those whose symptoms begin between 1 and 3 months afterward. A recent analysis of DAIR involving 769 episodes of post-operative PJI with symptom onset until day 90 after prosthesis placement observed no differences in prognosis based on the specific week where symptoms appeared ${ }^{59}$. Others have also observed a similar prognosis in patients whose symptoms start between the first 30 and 90 days and those with symptom onset within the first 30 days ${ }^{33,55,56}$. These findings challenge the use of 4 weeks after prosthesis placement to select suitable candidates for DAIR as being too strict, which could then be extended to 3 months ${ }^{10}$.

Duration of symptoms is the second chronological criterion. In post-operative infections, this variable is difficult to measure, since many signs and symptoms of inflammation overlap with those that are expected in the post-operative period, such as pain or local warmth. In contrast, it is a helpful measure for hematogenous infections that present suddenly with inflammatory signs on prosthetic joints that had been placed some months or years previously ${ }^{19,38}$.

The 21-day limit of symptom duration comes from the Zimmerli's trial ${ }^{58}$, in which none of the patients recruited presented with symptom duration of more than 3 weeks before surgical debridement. However, this does not necessarily mean that patients could not benefit from DAIR even if symptom duration was longer than 21 days. While it seems clear that the sooner the patient undergoes debridement, the better, no consistent reproducible time limit has been found across several studies $^{22,23,35,47,55,56,60-62}$. Indeed, from a retrospective point of view, a very short time interval between patient symptoms and undergoing debridement may be a surrogate marker of poor prognosis, since patients with more severe PJls (those with sepsis, high levels of CRP, or bacteremia) would be prioritized in the operating theater. This consideration represents an added difficulty to the search for a reliable time limit beyond which DAIR is not worth the effort.

In addition, it is possible that the chronology of infection, including both the age of the prosthesis and 
duration of symptoms, may have a differential influence on outcome, depending on the specific etiology, and furthermore on the specific bacterial strain, its virulence factors, and ability to form a mature biofilm ${ }^{63}$. Other variables, such as the activity of the antimicrobial treatment used, could also modify the importance of time. While Brandt et al. found that delaying debridement by more than 2 days was enough to worsen the prognosis of patients with staphylococcal PJI, mostly treated with $\beta$-lactams ${ }^{60}$, other series, mainly using rifampin-based combinations, raised this time limit to 10 days ${ }^{55}$.

\section{Failure despite following the rules: variables beyond the algorithms}

Treatment failure despite meeting Zimmerli's criteria is controversial. While some series have shown very good results with DAIR in very well-selected patients ${ }^{37}$, multiple observational studies have reported significant failure rates among patients who fulfilled the terms of the algorithm. In this respect, a number of risk factors for failure have been identified across these studies including variables related to the host's baseline condition, clinical presentation, and surgical and clinical management (Table 2). The bottom line of these studies is that the selection of candidates for DAIR should go beyond the standard recommendations and take some of these variables into account, along with PJI etiology when available.

To help with this decision, an interesting risk score was proposed by Tornero et al. ${ }^{51}$ based on a cohort of 222 patients with early post-surgical infection (defined according to the 90-day limit after prosthesis placement) who received DAIR within 21 days of symptom onset. The primary endpoint was failure in the first 60 days after DAIR. The KLICC score included five variables (kidney - chronic renal failure [2 points]; liver cirrhosis [1.5 points]; index surgery due to femoral neck fracture [1.5 points]; cemented prosthesis [2 points]; and CRP > $11.5 \mathrm{mg} / \mathrm{dL}$ [2.5 points]) and showed good discriminatory power (area under the curve 0.839). At scores $>3.5$, the sensitivity and specificity of predicting failure were $74 \%$ and $86 \%$, respectively ${ }^{51}$. This score was retrospectively validated by other investigators and showed a slightly lower sensitivity and specificity at the 3.5 limit $^{64,65}$. An alternative risk score, CRIME80, has also been published for hematogenous infections (i.e., late acute infections) (COPD, CRP > $150 \mathrm{mg} / \mathrm{L}$, rheumatoid arthritis, fracture as indication of prosthesis, male sex, exchange of removable components, and age $>80$ years $)^{50}$.
As was stated above, the etiology is commonly unknown when the decision is made, which is a significant limitation of algorithms and risk scores. Microbial etiology and the use of antibiotics with good activity against biofilm-embedded bacteria are certainly key factors for determining a given patient's prognosis. The benefits of using rifampin-based combinations to treat Staphylococcus aureus when the prosthesis is retained are well established in pre-clinical and clinical research, including a randomized clinical trial and several observational studies $^{55,58,66-69}$. Likewise, a dramatic improvement in prognosis has been shown using fluoroquinolones for infections caused by Gram-negative bacilli $(\mathrm{GNB})^{70-73}$. The largest published study of PJI caused by GNB managed with DAIR included 173 cases and showed that $79 \%$ of patients treated with ciprofloxacin were cured as compared with $41 \%$ who were not $(p=0.01)$, and the same benefit applied to specific types of bacteria such as Pseudomonas aeruginosa ( $88 \%$ vs. $45 \%, p=0.01$; $\mathrm{n}=42)$ and extended-spectrum beta-lactamase (ESBL)-producing Enterobacteriaceae (100\% vs. $46 \%$, $p=0.47 ; n=15)^{72}$. Ciprofloxacin is so important for treating these infections that it has still to be determined whether or not infections caused by multidrug-resistant (MDR) GNB imply a worse prognosis than those caused by GNB that are only resistant to fluoroquinolones. In a large study of cases of MDR PJI, the failure rate among cases managed with DAIR was $52 \%{ }^{74}$.

Unless the patient has a positive blood culture, knowing the etiology of PJI before DAIR requires a joint aspirate sample (feasible in knee prostheses, more complex in hip prostheses) and waiting for the bacteria to grow. Obtaining the antibiotic susceptibility profile takes extra time. Since the success of DAIR is time sensitive, the debate about whether to wait for pre-operative microbiological results or perform surgery as soon as possible remains open. At the recent Philadelphia International Consensus meeting, it was agreed that it was desirable to identify the microorganism but that this should not delay the performance of DAIR ${ }^{21}$.

Furthermore, even if we have the information on etiology beforehand, there is still controversy about the specific microorganisms that should discourage the performance of DAIR. While fungal infection clearly has a poor prognosis when managed with $\mathrm{DAIR}^{75}$, the odds of success for other microorganisms are variable (Table 3). From an overall perspective, a reasonably good outcome is expected against coagulase-negative staphylococci and fluoroquinolone-susceptible $\mathrm{GNB}^{46,61,72}$. While the prognosis of streptococcal PJI was thought to be favorable, a large case series 
Span J Med. 2021;1(2)

Table 2. Risk factors for failure after attempting DAIR

Risk factor

Baseline conditions

- Age

40,50

- Male sex

- Rheumatoid arthritis

$28,50,56$

- Smoking

83

- Chronic renal failure

- Liver cirrhosis

- High ASA score

- Obesity

- Immunosuppression

- Anemia

\section{Prosthesis features}

- Cemented prosthesis

- Revision prosthesis

- Femoral head fracture as indication of prosthesis

$45,50,51$

- Other indications

\section{Clinical presentation}

- Prosthesis age $>4$ weeks

- Duration of symptoms

$22,23,28,29,35,36,60-62$

- Radiological signs of infection

- Hematogenous infections*

$26,28,32,38,42,84,85$

- Bacteremia

$32,54,55$

- Sinus tract

- High levels of C-reactive protein or ESR

$27,28,32,48,50,51,55,86,87$

- Not meeting criteria for DAIR

$55,56,89,90$

- Macroscopic purulence surrounding the prosthesis

\section{Microbiology}

- Staphylococcus aureus

$12,22,26,34,46,47,50$

- Methicillin-resistant Staphylococcus aureus

$30,32,36,61$

- Staphylococci

27,44

- Enterococcus spp.

30

- Fluoroquinolone-resistant Gram-negative bacilli

72,86

- Microorganisms other than Gram-negative bacilli

72,90

- Non-susceptible microorganisms

23,30

- Polymicrobial infection

$32,55,92$ 
Table 2. Risk factors for failure after attempting DAIR (Continued)

\begin{tabular}{|l|c|}
\hline Risk factor & References \\
\hline $\begin{array}{l}\text { Management } \\
\text { - Arthroscopy } \\
\text { (instead of arthrotomy) }\end{array}$ & 47 \\
\hline - Need for an unplanned second debridement & $27,55,87$ \\
\hline - Not exchanging prosthetic removable components & $12,25,32,55,56$ \\
\hline - Using gentamicin-loaded cement beads & 48 \\
\hline - Not using Rifampin (staphylococci) & $55,58,67,69,83$ \\
\hline & Not using Fluoroquinolones \\
\hline
\end{tabular}

*Some authors have found a worse prognosis for late acute or hematogenous infection when the cause was Staphylococcus aureus but not other etiologies ${ }^{85}$. ASA: American Society of Anesthesiologists; ESR: erythorcyte sedimentation rate; DAIR: debridement, antibiotics, and implant retention.

challenged this and placed this infection in a mid-term outcome, similar to or slightly better than that of $S$. aureus ${ }^{56}$. The prognosis of methicillin-resistant $S$. aureus (MRSA) has also traditionally been regarded as poor ${ }^{76}$, but in a case series including a large number of episodes caused by MRSA, the outcome was similar to methicillin-susceptible strains as long as rifampin was used $^{55}$. The outcomes for fluoroquinolone-resistant GNB and enterococci are poor ${ }^{72,77}$.

All in all, the etiology of the infection and the antimicrobial treatment are crucial for establishing the prognosis of a given infection. In some patients, the existence of risk failures that reduce the odds of success could be appeased by the use antibiotics with good activity against biofilm-embedded bacteria.

\section{The penalty for failure: one shot, one opportunity?}

Patients who fail DAIR treatment are usually rescued by a two-step exchange procedure. The need for salvage therapy is always disappointing, for the patient and the attending medical team, as well as time and resource consuming. Every effort should be made to achieve a satisfactory outcome at the first attempt, and the choice of curative treatment should, therefore, be made carefully (Fig. 1).

As discussed above, the available algorithms and tools are useful for making decisions, but may at the same time lack specificity. A patient such as the one in the clinical case would have a KLICC score of over 3.5 (cemented prosthesis, indication for neck fracture, and high levels of CRP), which would theoretically preclude the possibility of DAIR. While this is the type of patient that nobody wants to operate on more often than is necessary, it is not altogether clear that prosthesis removal is really the best approach. The physiological stress involved in surgical debridement (prosthesis retention) or a longitudinal osteotomy (prosthesis removal) is not the same. In a cost-effectiveness analysis, Fisman et al. suggested that DAIR was a preferable option for elderly patients with stable prostheses ${ }^{13}$. In an interesting study of patients with infected knee prostheses, Djaza et al. also showed that functional outcome was better in patients with a successful DAIR than those who directly underwent a staged revision and similar to control patients with no infection ${ }^{17}$. On the other hand, the need for salvage therapy and repeated surgeries over a prosthetic joint may jeopardize the integrity of soft tissues, increase the odds of post-surgical joint stiffness, and eventually lead to poor functional results ${ }^{78}$.

Underlying these considerations is the question of whether or not patients who fail at the first attempt have a worse prognosis when they undergo salvage therapy; in other words, is the likelihood of being cured and having a good functional outcome in patients who go directly to the two-step exchange procedure the same when they receive it as salvage therapy after a failed DAIR? Is there just one shot, one opportunity? Otherwise, if the prognosis of salvage therapy is similar to a direct staged revision and the odds of success with DAIR are not too bad, trying DAIR would be an attractive choice.

Table 4 summarizes the studies that address this clinical question. Sherrel et al. observed a higher than 
Span J Med. 2021;1(2)

Table 3. Success rates of PJI managed by DAIR according to specific etiologies

\section{Microorganism}

Staphylococcus aureus

Reference

Success $-n / N(\%)$

$564 / 913(62 \%)$

Coagulase-negative staphylococci

Streptococcus spp.

Enterococcus spp.
Brandt et al., $1997^{60}$

Marculescu et al., $2006^{29}$

Barberán et al., $2006^{61}$

Aboltins et al., $2007^{93}$

Byren et al., 200946

Bradbury et al., 200976

Vilchez et al., $2011^{87}$

Senneville et al., $2011^{67}$

Lora-Tamayo et al., $2013^{55}$

Betz et al., $2015^{94}$

Lora-Tamayo et al., 2016 ${ }^{* 95}$

Lesens et al., $2018^{83}$

Muñoz-Gallego et al., $2020^{63}$

Becker et al., $2020^{68}$

Marculescu et al., $2006^{29}$

Barberán et al., $2006^{6}$

Byren et al., 200946

Lora-Tamayo et al., 2016 $6^{\mathrm{a}, 95}$

Becker et al., $2020^{68}$

\section{Meehan et al., $2003^{96}$}

Zeller et al., 200997

Sendi et al., $2011^{89}$

Corverc et al., $2011^{98}$

Bertz et al., $2015^{94}$

Lora-Tamayo et al., 2017

Akgün et al., 2017 ${ }^{99}$

Lam et al., 2018

Mahieu et al., 2019101

12/33 (36\%)

$4 / 32(13 \%)$

$13 / 21(62 \%)$

$17 / 19(89 \%)$

$34 / 47(72 \%)$

$3 / 19(16 \%)$

$40 / 53(75 \%)$

$32 / 41(78 \%)$

$182 / 328(55 \%)$

$22 / 29(76 \%)$

$31 / 34(91 \%)$

104/137 (76\%)

$29 / 55(53 \%)$

$41 / 65(63 \%)$

14/23 (61\%)

26/39 (67\%)

$21 / 26(81 \%)$

$10 / 10(100 \%)$

$15 / 16(94 \%)$

$17 / 19$ (89\%)

$4 / 6(66 \%)$

$13 / 20$ (65\%)

$3 / 3(100 \%)^{3}$

9/9 (100\%)

257/444 (58\%)

$4 / 6$ (67\%)

$53 / 64(82 \%)$

$19 / 38(50 \%)$

\begin{tabular}{l|c|}
\hline Raymond et al., $1995^{102}$ & $1 / 2(50 \%)$ \\
\hline Marculescu et al., 2006 & $2 / 3(66 \%)$ \\
\hline Rasouli et al., 2012 & 203 \\
\hline Tornero et al., 2014 & $4 / 10(40 \%)$ \\
\hline Duijf et al., 2015 & $44 / 94(47 \%)$ \\
\hline Kheir et al., 2017 & $29 / 44(66 \%)$ \\
\hline Thompson et al., 2019 & $13 / 33(39 \%)$ \\
\hline
\end{tabular}

$379 / 609$ (62\%)

(Range $50-100 \%$ )

86/114 (75\%)

(Range 61-100\%)

119/222 (54\%)

(Range 39-72\%) 
Table 3. Success rates of PJI managed by DAIR according to specific etiologies (Continued)

\begin{tabular}{|c|c|c|c|}
\hline Microorganism & Reference & \multicolumn{2}{|c|}{ Success - n/N (\%) } \\
\hline \multirow[t]{9}{*}{ Gram-negative bacilli } & & & $225 / 361(62 \%)^{d}$ \\
\hline & Marculescu et al., $2006^{29}$ & $4 / 6(66 \%)$ & (Range $26-88 \%$ ) \\
\hline & Hsieh et al., $2009^{62}$ & $7 / 27(26 \%)$ & \\
\hline & Martínez-Pastor et al., $2009^{86}$ & $35 / 47(74 \%)$ & \\
\hline & Aboltins et al., $2011^{70}$ & $15 / 17(88 \%)$ & \\
\hline & Zmistowsky et al., $2011^{90}$ & $7 / 10(70 \%)$ & \\
\hline & Rodríguez-Pardo et al., $2014^{72}$ & $118 / 174(68 \%)$ & \\
\hline & Bouige et al., 2019b,71 & $7 / 13(54 \%)$ & \\
\hline & Papadopoulos et al., 2019c,74 & $32 / 67(48 \%)$ & \\
\hline
\end{tabular}

expected frequency of failure, and Rajgopal et al. observed worse functional and microbiological results in patients undergoing prosthesis removal after DAIR ${ }^{15,78}$. However, Rajgopal's groups were unbalanced and included a higher proportion of difficult-to-treat microorganisms in patients with previous DAIR, and when these patients were excluded from the analysis the prognosis for both groups was similar ${ }^{78}$. These results have been contested by other researchers, who observed similar functional results and microbiological eradication for direct and salvage two-step prosthetic exchange $\mathrm{e}^{17,18,79-81}$. Overall, the question remains open: more studies are needed, with more patients, including hip prostheses and using a common outcome definition.

The observed heterogeneity across studies addressing the efficacy of DAIR also underlines the importance of focusing on adjustable risk factors, such as optimization of the patient's baseline conditions before and after DAIR treatment, using biofilm-active antimicrobials when possible, and thorough performance of surgical debridement. Several studies in this respect observed a better prognosis when the removable components of the prosthesis were exchanged during debridement ${ }^{12,25,32,50,55,56}$.

\section{The decision}

Saving an infected foreign body is difficult. Optimizing management involves selecting the correct patient, the right infection, and the most appropriate surgical and medical treatment. Current guidelines provide a helpful approach to decision making. Expertise, knowledge, and multidisciplinary consensus will put any given patient with a specific infection in the relevant context.

The clinical case described herein is a common example of real-life clinical practice. When considering DAIR for this patient, we should note that duration of symptoms was less than 21 days. Importantly, the prosthesis appeared to be well fixed, and the skin and periprosthetic soft tissues were in good condition. However, the patient had a post-operative infection that a number of guidelines would define as chronic ${ }^{21,52,53}$. We have no information about the causative microorganism so that we cannot be sure of the availability of antibiotics with good activity against biofilm-embedded bacteria. Finally, this patient would have a KLICC score of 6 points, well beyond the proposed cut-off of $3.5^{51}$.

Nevertheless, other authors would consider the same infection as early post-operative and with the same odds of success as those with symptoms beginning in the first 4 weeks ${ }^{55,56,59}$. Of importance, this patient has a revision hip and a knee prosthesis on the same limb and so has little remaining bone stock, which would make prosthesis exchange difficult and completion of the procedure could not be guaranteed. Finally, although we cannot exclude an infection caused by a MDR microorganism, this was the first episode and there was no previous antibiotic exposure so that the microorganism may well be sensitive. Better functional results may be obtained with DAIR than with a direct attempt at staged revision ${ }^{17}$. In case of failure, some authors would argue that a two-step salvage exchange procedure could be undertaken with a reasonable guarantee of good results ${ }^{18,80,81}$. 
Table 4. Studies addressing the prognosis of patients undergoing prosthesis removal as salvage therapy after DAIR

\begin{tabular}{|c|c|c|c|c|c|c|}
\hline \multirow[t]{2}{*}{ Reference } & \multirow{2}{*}{$\begin{array}{l}\text { Type of } \\
\text { prosthesis }\end{array}$} & \multicolumn{2}{|c|}{ Number of patients } & \multirow[t]{2}{*}{ Etiology } & \multirow[t]{2}{*}{ Microbiological results } & \multirow[t]{2}{*}{ Functional results } \\
\hline & & Direct 2SEP & Salvage 2SEP & & & \\
\hline $\begin{array}{l}\text { Sherrel et al., } \\
2011^{15}\end{array}$ & Knees & $\begin{array}{l}\text { (Historical } \\
\text { controls) }\end{array}$ & 83 & Various & $\begin{array}{l}\text { Failure } 34 \% \\
\text { (Historical controls: } 11 \% \text { ) }\end{array}$ & - \\
\hline $\begin{array}{l}\text { Kubista et al., } \\
2012^{79}\end{array}$ & Knees & 314 & 54 & Various & $\begin{array}{l}\text { Overall failure of } 2 \text { SEP } 15 \% \\
\text { Risk of failure for salvage } \\
\text { 2SEP: HR } 1.46 ; P=0.16 \text {. }\end{array}$ & - \\
\hline $\begin{array}{l}\text { Dzaja et al., } \\
2015^{\mathrm{a}, 17}\end{array}$ & Knees & 91 & 33 & Various & - & $\begin{array}{l}\text { Similar functional } \\
\text { results }\end{array}$ \\
\hline $\begin{array}{l}\text { Brimmo et al., } \\
2016^{18}\end{array}$ & Knees & 693 & 57 & Various & $\begin{array}{l}\text { Failure at } 4 \text { years: } \\
\text { Direct } 2 \text { SEP }-17.5 \% \\
\text { Salvage } 2 \text { SEP }-8.7 \% \\
(p=0.131)\end{array}$ & - \\
\hline $\begin{array}{l}\text { Herman et al., } \\
2017^{\mathrm{a}, 80}\end{array}$ & Hips & 68 & 28 & Various & - & $\begin{array}{l}\text { Similar functional } \\
\text { results }\end{array}$ \\
\hline $\begin{array}{l}\text { Nodzo et al., } \\
2017^{81}\end{array}$ & Knees & 132 & 45 & Various & $\begin{array}{l}\text { Failure } 17.5 \% \text { direct } 2 \text { SEP } \\
\text { Failure } 17.8 \% \text { salvage } \\
\text { 2SEP }\end{array}$ & - \\
\hline $\begin{array}{l}\text { Raigopal et al., } \\
2018^{78}\end{array}$ & Knees & 96 & 88 & Various & $\begin{array}{l}\text { Failure } 15.6 \% \text { direct } 2 \text { SEP } \\
\text { Failure } 23.9 \% \text { salvage } \\
2 \text { SEP }, c\end{array}$ & $\begin{array}{l}\text { Range of motion } 96.4^{\circ} \\
\text { direct } 2 \text { SEP } \\
\text { Range of motion } 88.4^{\circ} \\
\text { salvage } 2 \text { SEPb }\end{array}$ \\
\hline
\end{tabular}

aFrom the London Health Science Center (London, Ontario, Canada).

bStatistically significant difference.

${ }^{c}$ A higher proportion of MRSA was observed among patients in the salvage 2SEP group; when MRSA, P. aeruginosa, and methicillin-resistant $S$. epidermidis were excluded, no significant differences in microbiological outcome were observed.

2SEP: 2-step exchange procedure; MRSA: methicillin-resistant $S$. aureus; HR: hazard ratio.

To sum up, we would discuss this case with our colleagues, orthopedists, and microbiologists, and present the pros and cons to the patient and his family. If there is agreement, we would advocate DAIR as soon as possible, including the exchange of removable components, if feasible. Finally, we would optimize the patient's perioperative condition and comorbidity, and ensure the best antimicrobial treatment. In case of failure, we would favor a two-step exchange procedure.

\section{Acknowledgments}

We are thankful to Janet Dawson for reviewing the English manuscript. We are also indebted to Emilio Delgado (Department of Traumatology and Orthopedic Surgery, Hospital Univeristario 12 de Octubre, Madrid) and $\mathrm{M}^{\mathrm{a}}$ Ángeles Meléndez (Department of Microbiology, Hospital Univeristario 12 de Octubre, Madrid), for their critical review of the text.

\section{Funding}

This work was made with the support of Fondo de Investigación Sanitaria (Instituto de Salud Carlos III, Ministerio de Ciencia e Innovación; PI018/01623). M.M-L. is supported by the Subprograma Río Hortega, Instituto de Salud Carlos III, Subdirección General de Redes y Centros de Investigación y Ciencia, Ministerio de Ciencia, Innovación y Universidades, Spain (CM19/00226).

\section{Conflicts of interest}

The authors declare that they have no conflicts of interest.

\section{Ethical disclosures}

Protection of human and animal subjects. The authors declare that no experiments were performed on humans or animals for this study. 
Confidentiality of data. The authors declare that no patient data appear in this article.

Right to privacy and informed consent. The authors declare that no patient data appear in this article.

\section{References}

1. Kurtz SM, Lau E, Watson $\mathrm{H}$, et al. Economic burden of periprosthetic joint infection in the United States. J Arthroplasty. 2012;27:61-50.

2. Del Pozo JL, Patel R. Clinical practice. Infection associated with prosthetic joints. N Engl J Med. 2009;361:787-94.

3. Costerton JW, Stewart PS, Greenberg EP. Bacterial biofilms: a common cause of persistent infections. Science. 1999;284:1318-22.

4. Bozic KJ, Ries MD. The impact of infection after total hip arthroplasty on hospital and surgeon resource utilization. J Bone Joint Surg Am. 2005;87:1746-51.

5. Knebel C, Menzemer J, Pohlig F, et al. Peri-prosthetic joint infection of the knee causes high levels of psychosocial distress: a prospective cohort study. Surg Infect (Larchmt). 2020;21:877-83.

6. Rietbergen L, Kuiper JW, Walgrave S, et al. Quality of life after staged revision for infected total hip arthroplasty: a systematic review. Hip Int. 2016;26:311-8.

7. Peel TN, Cheng AC, Lorenzo YP, et al. Factors influencing the cost of prosthetic joint infection treatment. J Hosp Infect. 2013;85:213-9.

8. Peel TN, Dowsey MM, Buising KL, et al. Cost analysis of debridement and retention for management of prosthetic joint infection. Clin Microbio Infect. 2013;19:181-6.

9. Peel TN, de Steiger R. How to manage treatment failure in prosthetic joint infection. Clin Microbiol Infect. 2020;26:1473-80.

10. Ariza J, Cobo J, Baraia-Etxaburu J, et al. Executive summary of management of prosthetic joint infections. Clinical practice guidelines by the Spanish Society of Infectious Diseases and Clinical Microbiology (SEIMC). Enferm Infecc Microbiol Clin. 2017;35: 189-95.

11. Darouiche RO. Treatment of infections associated with surgical implants. N Engl J Med. 2004;350:1422-9.

12. Choi HR, von Knoch F, Zurakowski D, et al. Can implant retention be recommended for treatment of infected TKA? Clin Orthop Relat Res. 2011;469:961-9.

13. Fisman DN, Reilly DT, Karchmer AW, et al. Clinical effectiveness and cost-effectiveness of 2 management strategies for infected total hip arthroplasty in the elderly. Clin Infect Dis. 2001;32:419-30.

14. Singh N, Nair R, Goto M, et al. Risk of recurrent Staphylococcus aureus prosthetic joint infection in rheumatoid arthritis patients-a nationwide cohort study. Open Forum Infect Dis. 2019;6:ofz451.

15. Sherrell JC, Fehring TK, Odum S, et al. The Chitranjan Ranawat Award: fate of two-stage reimplantation after failed irrigation and débridement for periprosthetic knee infection. Clin Orthop Relat Res. 2011;469:18-25.

16. Lum ZC, Holland CT, Meehan JP. Systematic review of single stage revision for prosthetic joint infection. World J Orthop. 2020;11:559-72.

17. Dzaja I, Howard J, Somerville L, et al. Functional outcomes of acutely infected knee arthroplasty: a comparison of different surgical treatment options. Can J Surg. 2015;58:402-7.

18. Brimmo O, Ramanathan D, Schiltz NK, et al. Irrigation and debridement before a 2-stage revision total knee arthroplasty does not increase risk of failure. J Arthroplasty. 2016;31: 461-4.

19. Zimmerli W, Trampuz A, Ochsner PE. Prosthetic-joint infections. N Engl J Med. 2004;351:1645-54.

20. Aboltins C, Dowsey M, Peel T, et al. Good quality of life outcomes after treatment of prosthetic joint infection with debridement and prosthesis retention. J Orthop Res. 2016;34:898-902.

21. Argenson JN, Arndt M, Babis G, et al. Hip and knee section, treatment, debridement and retention of implant: proceedings of international consensus on orthopedic infections. J Arthroplasty. 2019;34:S399-S419.

22. Schoifet SD, Morrey BF. Treatment of infection after total knee arthroplasty by debridement with retention of the components. J Bone Joint Surg Am. 1990;72:1838-90.

23. Burger RR, Basch $\mathrm{T}$, Hopson $\mathrm{CN}$. Implant salvage in infected total knee arthroplasty. Clin Orthop Relat Res. 1991;(273):105-12.

24. Geurts JA, Janssen DM, Kessels AG, et al. Good results in postoperative and hematogenous deep infections of 89 stable total hip and knee replacements with retention of prosthesis and local antibiotics. Acta Orthop. 2013:84:509-16.

25. Hirsiger S, Betz M, Stafylakis D, et al. the benefice of mobile parts' exchange in the management of infected total joint arthroplasties with prosthesis retention (DAIR procedure). J Clin Med. 2019;8:226.

26. Iza K, Foruria X, Moreta J, et al. DAIR (debridement, antibiotics and implant retention) less effective in hematogenous total knee arthroplasty infections. J Orthop Surg Res. 2019;14:278.
27. Jacobs AME, Valkering LJJ, Bénard M, et al. Evaluation one year after DAIR treatment in 91 suspected early prosthetic joint infections in primary knee and hip arthroplasty. J Bone Jt Infect. 2019;4: 238-44.

28. Kuiper JW, Vos SJ, Saouti R, et al. Prosthetic joint-associated infections treated with DAIR (debridement, antibiotics, irrigation, and retention): analysis of risk factors and local antibiotic carriers in 91 patients. Acta Orthop. 2013:84:380-6.

29. Marculescu CE, Berbari EF, Hanssen AD, et al. Outcome of prosthetic joint infections treated with debridement and retention of components. Clin Infect Dis. 2006;42: 471-8.

30. Soriano A, García S, Bori G, et al. Treatment of acute post-surgical infection of joint arthroplasty. Clin Microbiol Infect. 2006;12:930-3.

31. Puhto AP, Puhto T, Niinimäki T, et al. Predictors of treatment outcome in prosthetic joint infections treated with prosthesis retention. Int Orthop. 2015;39:1785-91.

32. Shohat N, Goswami K, Tan TL, et al. 2020 Frank stinchfield award: identifying who will fail following irrigation and debridement for prosthetic joint infection. Bone Joint J. 2020;102- B:11-9.

33. Achermann $Y$, Stasch $P$, Preiss $S$, et al. Characteristics and treatment outcomes of 69 cases with early prosthetic joint infections of the hip and knee. Infection. 2014:42:511-9.

34. Swenson RD, Butterfield JA, Irwin TJ, et al. Preoperative anemia is associated with failure of open debridement polyethylene exchange in acute and acute hematogenous prosthetic joint infection. J Arthroplasty. 2018;33:1855-60.

35. Tattevin $P$, Crémieux AC, Pottier $P$, et al. Prosthetic joint infection: when can prosthesis salvage be considered? Clin Infect Dis. 1999;29:292-5.

36. Triantafyllopoulos GK, Poultsides LA, Sakellariou VI, et al. Irrigation and debridement for periprosthetic infections of the hip and factors determining outcome. Int Orthop. 2015;39:1203-9.

37. Tschudin-Sutter S, Frei R, et al. Validation of a treatment algorithm for orthopaedic implant-related infections with device-retention-results from a prospective observational cohort study. Clin Microbiol Infect. 2016;22:457.e1-9.

38. Tsukayama DT, Estrada R, Gustilo RB. Infection after total hip arthroplasty. A study of the treatment of one hundred and six infections. J Bone Joint Surg Am. 1996;78:512-23.

39. de Vries L, van der Weegen W, Neve WC, et al. The effectiveness of debridement, antibiotics and irrigation for periprosthetic joint infections after primary hip and knee arthroplasty. A 15 years retrospective study in two community hospitals in the Netherlands. J Bone Jt Infect. 2016;1:20-4

40. Westberg M, Grøgaard B, Snorrason F. Early prosthetic joint infections treated with debridement and implant retention: 38 primary hip arthroplasties prospectively recorded and followed for median 4 years. Acta Orthop. 2012;83:227-32.

41. Zhang $\mathrm{CF}, \mathrm{He} \mathrm{L}$, Fang $\mathrm{XY}$, et al. Debridement, antibiotics, and implant retention for acute periprosthetic joint infection. Orthop Surg. 2020;12:463-70.

42. Zhu MF, Kim K, Cavadino A, et al. Success rates of debridement, antibiotics, and implant retention in 230 infected total knee arthroplasties: implications for classification of periprosthetic joint infection. J Arthroplasty. 2021;36:305-100

43. Ascione $\mathrm{T}$, Pagliano $\mathrm{P}$, Mariconda $\mathrm{M}$, et al. Factors related to outcome of early and delayed prosthetic joint infections. J Infect. 2015;70:30-6.

44. Azzam KA, Seeley M, Ghanem E, et al. Irrigation and debridement in the management of prosthetic joint infection: traditional indications revisited. J Arthroplasty. 2010;25:1022-7.

45. Bergkvist M, Mukka SS, Johansson L, et al. Debridement, antibiotics and implant retention in early periprosthetic joint infection. Hip Int. 2016;26:138-43

46. Byren I, Bejon P, Atkins BL, Angus B, Masters S, McLardy-Smith P, et al. One hundred and twelve infected arthroplasties treated with "DAIR" (debridement, antibiotics and implant retention): antibiotic duration and outcome. J Antimicrob Chemother. 2009;63:1264-71.

47. Cobo J, Miguel LG, Euba G, et al. Early prosthetic joint infection: outcomes with debridement and implant retention followed by antibiotic therapy. Clin Microbiol Infect. 2011;17:1632-7.

48. Deijkers RL, Pijls BG. Debridement, antibiotics, and implant retention with the direct anterior approach for acute periprosthetic joint infection following primary THA. JBJS Open Access. 2020;5:e0062.

49. Fehring TK, Odum SM, Berend KR, et al. Failure of irrigation and débridement for early postoperative periprosthetic infection. Clin Orthop Relat Res. 2013;471:250-7.

50. Wouthuyzen-Bakker M, Sebillotte M, Lomas J et al. Clinical outcome and risk factors for failure in late acute prosthetic joint infections treated with debridement and implant retention. J Infect. 2019;78:40-7.

51. Tornero E, Morata L, Martínez-Pastor JC, et al. KLIC-score for predicting early failure in prosthetic joint infections treated with debridement, implant retention and antibiotics. Clin Microbiol Infect. 2015;21:786.e9-17.

52. Osmon DR, Berbari EF, Berendt AR, et al. Executive summary: diagnosis and management of prosthetic joint infection: clinical practice guidelines by the Infectious Diseases Society of America. Clin Infect Dis. 2013;56:1-0. 
53. Scientifique A. Méthode Recommandation Pour la Pratique Clinique Recommandation de Bonne Pratique; 2014. Available from: http://www. has-sante.fr. [Last accessed on $2021 \mathrm{Jan}^{12}$.

54. Hengzhuang W, Wu H, Ciofu O, Song Z, Høiby N. Pharmacokinetics/ pharmacodynamics of colistin and imipenem on mucoid and nonmucoid Pseudomonas aeruginosa biofilms. Antimicrob Agents Chemother. 2011:55:4469-74.

55. Lora-Tamayo J, Murillo O, Iribarren JA, Soriano A, Sánchez-Somolinos $\mathrm{M}$, Baraia-Etxaburu JM, et al. A large multicenter study of methicillin-susceptible and methicillin-resistant Staphylococcus aureus prosthetic join infections managed with implant retention. Clin Infect Dis. 2013:56:182-94.

56. Lora-Tamayo J, Senneville É, Ribera A, et al. The not-so-good prognosis of streptococcal periprosthetic joint infection managed by implant retention: the results of a large multicenter study. Clin Infect Dis. 2017;64:1742-52.

57. Bouaziz A, Uçkay I, Lustig S, et al. Non-compliance with IDSA guidelines for patients presenting with methicillin-susceptible Staphylococcus aureus prosthetic joint infection is a risk factor for treatment failure. Med Mal Infect. 2018;48:207-11.

58. Zimmerli W, Widmer AF, Blatter M, et al. Role of rifampin for treatmen of orthopedic implant-related staphylococcal infections: a randomized controlled trial. Foreign-Body Infection (FBI) study group. JAMA. 1998:279:1537-41.

59. Löwik CA, Parvizi J, Jutte PC, et al. Debridement, antibiotics, and implan retention is a viable treatment option for early periprosthetic joint infection presenting more than 4 weeks after index arthroplasty. Clin Infect Dis. 2020;71:630-6

60. Brandt CM, Duffy MC, Berbari EF, et al. Staphylococcus aureus prosthetic joint infection treated with prosthesis removal and delayed reimplantation arthroplasty. Mayo Clin Proc. 1999;74:553-8.

61. Barberán J, Aguilar L, Carroquino G, et al. Conservative treatment of staphylococcal prosthetic joint infections in elderly patients. Am J Med. 2006:119:993.e7-10.

62. Hsieh PH, Lee MS, Hsu KY, et al. Gram-negative prosthetic joint infections: risk factors and outcome of treatment. Clin Infect Dis. 2009;49:1036-

63. Muñoz-Gallego I, Viedma E, Esteban J, et al. Genotypic and phenotypic characteristics of Staphylococcus aureus prosthetic joint infections: insight on the pathogenesis and prognosis of a multicenter prospective cohort. Open Forum Infect Dis. 2020;7:ofaa344.

64. Löwik CA, Jutte PC, Tornero E, et al. Predicting failure in early acute prosthetic joint infection treated with debridement, antibiotics, and implan retention: external validation of the KLIC score. J Arthroplasty. 2018;33:2582-7.

65. Jiménez-Garrido C, Gómez-Palomo JM, Rodríguez-Delourme I, et al Correction to: the kidney, liver, index surgery and $C$ reactive protein score is a predictor of treatment response in acute prosthetic joint infection. Int Orthop. 2018;42:39

66. Zimmerli W, Sendi P. Role of rifampin against staphylococcal biofilm infections. Antimicrob Agents Chemother. 2019;63:e01746-18.

67. Senneville E, Joulie D, Legout L, et al. Outcome and predictors of treatment failure in total hip/knee prosthetic joint infections due to Staphylo coccus aureus. Clin Infect Dis. 2011;53:334-40.

68. Becker A, Kreitmann L, Triffaut-Fillit C, et al. Duration of rifampin therapy is a key determinant of improved outcomes in early-onset acute prosthetic joint infection due to Staphylococcus treated with a debridement, antibiotics and implant retention (DAIR): a retrospective multicenter study in France. J Bone Jt Infect. 2020;5:28-34.

69. Widmer AF, Gaechter A, Ochsner PE, et al. Antimicrobial treatment of orthopedic implant-related infections with rifampin combinations. 1992:14:1251-3.

70. Aboltins CA, Dowsey MM, Buising KL, et al. Gram-negative prosthetic join infection treated with debridement, prosthesis retention and antibiotic regimens including a fluoroquinolone. Clin Microbiol Infect. 2011:17:862-7.

71. Bouige A, Fourcade C, Bicart-See A, et al. Characteristics of Enterobac ter cloacae prosthetic joint infections. Med Mal Infect. 2019;49:511-8.

72. Rodríguez-Pardo D, Pigrau C, Lora-Tamayo J, et al. Gram-negative prosthetic joint infection: outcome of a debridement, antibiotics and implant retention approach. A large multicentre study. Clin Microbiol Infect. 2014;20:0911-9.

73. Widmer AF, Wiestner A, Frei $\mathrm{R}$, et al. Killing of nongrowing and adherent Escherichia coli determines drug efficacy in device-related infections. Antimicrob Agents Chemother. 1991;35:741-6.

74. Papadopoulos A, Ribera A, Mavrogenis AF, et al. Multidrug-resistant and extensively drug-resistant gram-negative prosthetic joint infections: role of surgery and impact of colistin administration. Int $\mathrm{J}$ Antimicrob Agents. 2019;53:294-301.

75. Kuiper JW, van den Bekerom MP, van der Stappen J, et al. 2-stage revision recommended for treatment of fungal hip and knee prosthetic joint infections. Acta Orthop. 2013;84:517-23.

76. Bradbury T, Fehring TK, Taunton M, et al. The fate of acute methicillin-resistant Staphylococcus aureus periprosthetic knee infections treated by open debridement and retention of components. J Arthroplasty. 2009;24:101-4
77. Tornero E, Senneville E, Euba G, et al. Characteristics of prosthetic joint infections due to Enterococcus sp. and predictors of failure: a multi-national study. Clin Microbiol Infect. 2014;20:1219-24.

78. Rajgopal A, Panda I, Rao A, et al. Does prior failed debridement compromise the outcome of subsequent two-stage revision done for periprosthetic joint infection following total knee arthroplasty? J Arthroplasty. 2018;33:2588-94.

79. Kubista B, Hartzler RU, Wood CM, et al. Reinfection after two-stage revision for periprosthetic infection of total knee arthroplasty. Int Orthop. 2012;36:65-71.

80. Herman BV, Nyland M, Somerville L, et al. Functional outcomes of infected hip arthroplasty: a comparison of different surgical treatment options. Hip Int. 2017;27:245-50.

81. Nodzo SR, Boyle KK, Nocon AA, et al. The influence of a failed irrigation and debridement on the outcomes of a subsequent 2-stage revision knee arthroplasty. J Arthroplasty. 2017;32:2508-12.

82. Société de Pathologie Infectieuse de Langue Française (SPILF), Collège des Universitaires de Maladies Infectieuses et Tropicales (CMIT), Groupe de Pathologie Infectieuse Pédiatrique (GPIP), Société Française d’Anesthésie et de Réanimation (SFAR), Société Française de Chirurgie Orthopédique et Traumatologique (SOFCOT), Société Française d'Hygiène Hospitalière (SFHH), et al. Recommendations for bone and joint prosthetic device infections in clinical practice (prosthesis, implants, osteosynthesis). Société de Pathologie Infectieuse de Langue Française. Med Mal Infect. 2010;40:185-211.

83. Lesens O, Ferry T, Forestier E, et al. Should we expand the indications for the DAIR (debridement, antibiotic therapy, and implant retention) procedure for Staphylococcus aureus prosthetic joint infections? A multicenter retrospective study. Eur J Clin Microbiol Infect Dis. 2018;37: 1949-56.

84. Vilchez F, Martínez-Pastor JC, García-Ramiro S, et al. Efficacy of debridement in hematogenous and early post-surgical prosthetic joint infections. Int J Artif Organs. 2011;34:863-9.

85. Wouthuyzen-Bakker M, Sebillotte M, Huotari K, et al. lower success rate of débridement and implant retention in late acute versus early acute periprosthetic joint infection caused by Staphylococcus spp. results from a matched cohort study. Clin Orthop Relat Res. 2020;478:1348-55.

86. Martínez-Pastor JC, Muñoz-Mahamud E, Vilchez F, et al. Outcome of acute prosthetic joint infections due to gram-negative bacilli treated with open debridement and retention of the prosthesis. Antimicrob Agents Chemother. 2009;53:4772-7.

87. Vilchez F, Martínez-Pastor JC, García-Ramiro S, et al. Outcome and predictors of treatment failure in early post-surgical prosthetic joint infections due to Staphylococcus aureus treated with debridement. Clin Microbiol Infect. 2011;17:439-44.

88. Martel-Laferrière $\mathrm{V}$, Laflamme $\mathrm{P}$, Ghannoum $\mathrm{M}$, et al. Treatment of prosthetic joint infections: validation of a surgical algorithm and proposal of a simplified alternative. J Arthroplasty. 2013;28:395-400.

89. Sendi P, Christensson B, Uçkay I, et al. Group B Streptococcus in prosthetic hip and knee joint-associated infections. J Hosp Infect. 2011;79:64-9.

90. Zmistowski B, Fedorka CJ, Sheehan E, Deirmengian G, Austin MS, Parvizi J. Prosthetic joint infection caused by gram-negative organisms. J Arthroplasty. 2011;26:104-8.

91. Tornero E, Morata L, Martínez-Pastor JC, et al. Prosthetic joint infections due to methicillin-resistant and methicillin-susceptible staphylococci treated with open debridement and retention of the prosthesis. Rev Esp Quimioter. 2013;26:353-9.

92. Tornero E, Morata L, Martínez-Pastor JC, et al. Importance of selection and duration of antibiotic regimen in prosthetic joint infections treated with debridement and implant retention. $J$ Antimicrob Chemother. 2016;71:1395-401

93. Aboltins CA, Page MA, Buising KL, et al. Treatment of staphylococcal prosthetic joint infections with debridement, prosthesis retention and oral rifampicin and fusidic acid. Clin Microbiol Infect. 2007;13:586-91.

94. Betz M, Abrassart S, Vaudaux $P$, et al. Increased risk of joint failure in hip prostheses infected with Staphylococcus aureus treated with debridement, antibiotics and implant retention compared to Streptococcus. Int Orthop. 2015;39:397-401.

95. Lora-Tamayo J, Euba G, Cobo J. Short-versus long-duration levofloxacin plus rifampicin for acute staphylococcal prosthetic joint infection managed with implant retention: a randomised clinical trial. Int J Antimicrob Agents 2016;48:310-6.

96. Meehan AM, Osmon DR, Duffy MC, et al. Outcome of penicillin-susceptible streptococcal prosthetic joint infection treated with debridement and retention of the prosthesis. Clin Infect Dis. 2003;36:845-9.

97. Zeller V, Lavigne M, Leclerc P, et al. Group B streptococcal prosthetic joint infections: a retrospective study of 30 cases. Presse Med. 2009;38:1577-84.

98. Corvec S, Illiaquer M, Touchais S, et al. Clinical features of group B Streptococcus prosthetic joint infections and molecular characterization of isolates. J Clin Microbiol. 2011;49:380-2. 
99. Akgün D, Trampuz A, Perka C, Renz N. High failure rates in treatment of streptococcal periprosthetic joint infection: results from a seven-year retrospective cohort study. Bone Joint J. 2017;99-B:653-9.

100. Lam A, Rasmussen M, Thompson O. Successful outcome for patients with streptococcal prosthetic joint infections a retrospective population-based study. Infect Dis (Lond). 2018;50:593-600.

101. Mahieu R, Dubée V, Seegers V, et al. The prognosis of streptococca prosthetic bone and joint infections depends on surgical management-A multicenter retrospective study. Int J Infect Dis. 2019;85:175-81.

102. Raymond NJ, Henry J, Workowski KA. Enterococcal arthritis: case report and review. Clin Infect Dis. 1995;21:516-22.
103. Rasouli MR, Tripathi MS, Kenyon R, et al. Low rate of infection control in enterococcal periprosthetic joint infections. Clin Orthop Relat Res. 2012;470:2708-16.

104. Duijf SV, Vos FJ, Meis JF, Goosen JH. Debridement, antibiotics and implant retention in early postoperative infection with Enterococcus sp. Clin Microbiol Infect. 2015;21:e41-2.

105. Kheir MM, Tan TL, Higuera C. Periprosthetic joint infections caused by enterococci have poor outcomes. J Arthroplasty. 2017;32:933-47.

106. Thompson O, Rasmussen M, Stefánsdóttir A. A population-based study on the treatment and outcome of enterococcal prosthetic joint infections. A consecutive series of 55 cases. J Bone Jt Infect. 2019;4:285-91. 